Functional

Ecology 2002

16, $742-749$

\title{
Nutrients, arbuscular mycorrhizas and competition interact to influence seed production and germination success in Achillea millefolium
}

\author{
V. J. ALLiSON*† \\ Department of Ecology and Evolutionary Biology, University of Michigan, 830 N. University Ave, Ann Arbor, \\ MI 48109, USA
}

\section{Summary}

1. Environmental variables that positively affect one aspect of plant fitness, may have no effect, or even negatively affect some other component of fitness.

2. Using individuals of Achillea millefolium grown under field conditions in Michigan, USA, the hypothesis was tested that seed number was determined largely by plant biomass, while seed germination success depends on tissue nutrient concentrations. The impact was assessed of four biotic and abiotic factors on seed number and germination success: root competition, shoot competition, fertilizer, and removal of fungi by fungicide application.

3. Using a path analysis, it was found that total plant biomass positively affected both seed number and germination success, while inclusion of other variables did not greatly affect the amount of variation the model was able to explain. Fertilizer and fungicide increased, while root and shoot competition decreased both seed number and germination.

4. Fungicide applied to the maternal plant increased biomass but decreased tissue phosphorus concentrations. In species where germination responds to nutrient concentrations, the potential exists for opposing impacts of environmental treatments on different components of fitness.

5. This study suggests that environmental impacts on seed number will outweigh impacts on germination success under field conditions, and that biomass is an adequate surrogate for fitness in herbaceous plants.

Key-words: Biomass, fitness, maternal environment, path analysis, tissue nutrient concentrations

Functional Ecology (2002) 16, 742-749

\section{Introduction}

Fitness is a measure of the genetic contribution that an individual makes to the next generation (Begon, Harper \& Townsend 1996). Two factors of primary importance in determining the fitness of a plant are the number of seeds produced, and the germination success of those seeds, because the number of potential seedlings is the product of seed number and the proportion of those seeds that germinate. Seed number and success can be influenced by the maternal plant's genetic characteristics and by its environment, and these environmental factors can, in turn, be physical or biotic. For example, availability of soil nutrients to the maternal plant could potentially affect seed produc-

*E-mail: vallison@anl.gov

$†$ Present address: Environmental Research Division, Bldg 203, E-133, Argonne National Laboratory, 9700 S. Cass Ave, Argonne, IL 60647, USA tion and success, as could interactions with other plants. Interactions with components of the soil biota such as fungi may also be important, particularly those that interact very closely with plants, such as arbuscular mycorrhizal fungi. Environmental impacts are particularly interesting because they may positively affect one component that determines fitness while simultaneously negatively affecting a second component of fitness. If changes in seed number and germination success are negatively correlated, measures of fitness that take into account only one or the other may be misleading, as the net effect depends on both.

In this paper, I focus on how seed number and germination success are influenced by four environmental factors: fertilizer, arbuscular mycorrhizal (AM) fungi, root competition, and shoot competition. Fertilizer directly increases nutrient availability to the maternal plant. Arbuscular mycorrhizal fungi can increase nutrients (especially phosphorus) availability to the plant, but may simultaneously drain carbon, as the 
Environmental impacts on fitness of Achillea

(C) 2002 British Ecological Society, Functional Ecology, 16, $742-749$
AM fungi require energy from the plant in the form of sugars (Read 1991). Root and shoot competition are also important determinants of plant success, and therefore are likely to influence seed number and germination. Root competition can locally reduce soil nutrient availability, while shoot competition can reduce light availability and hence potential carbon fixation (see papers in Grace \& Tilman 1990).

These four factors can potentially alter plant fitness through impacts on seed number and germination success, and not necessarily in the same direction. Although not generally stated explicitly, variation in seed yield is likely to be largely due to variation in total plant biomass (Cheplick 2001). Both root and shoot competition are likely to reduce seed numbers by decreasing plant size (Cheplick 2001; Samson \& Werk 1986). In contrast, fertilizer increases seed number. For example, Holt (1988) found that although nitrogen fertilizer had a negative effect on mean seed weight of Canary grass, it significantly increased seed yield by increasing the number of seeds produced. Similarly, Weiner et al. (1997) and Wulff et al. (1999) found that increased nutrients significantly increased the size of the maternal plant and the number of seeds produced in Centaurea maculosa and Chenopodium album, respectively. Similarly, AM fungi can influence the number of seeds produced. For example, Bryla \& Koide (1990) found that AM plants of Lycopersicon esculentum had increased numbers of seeds per plant, largely due to increased fruit numbers.

In contrast to seed yield, the germination success of seeds appears to depend largely on the concentration of nutrients in tissues of the maternal plants, rather than on biomass. Maternal plants with high nutrient concentrations produce large seeds with high nutrient concentrations, and increased seed size and nutrient concentrations have been shown to increase seed germination success (Aarssen \& Burton 1990; Cheplick \& Sung 1998; Sills \& Nienhuis 1995). This is thought to be due to changes in seed mineral composition, with maternal environment shown to affect oil content, fatty acid composition and protein content in a range of seeds (reviewed by Roach \& Wulff 1987). These changes may also be accompanied by changes in seed coat structure; changes that alter permeability may affect germination by preventing leaching of inhibitors, or by interfering with water absorption and embryo enlargement (Raven, Evert \& Eichhorn 1999). Because these compositional and structural changes in the seed commonly occur simultaneously, the mechanisms by which they affect seed germination are difficult to separate (Roach \& Wulff 1987).

Seed size and nutrient concentrations are known to respond to both fertilizer (Parrish \& Bazzaz 1985) and AM fungi (Al-Kariki \& Clark 1999; Bethlenfalvay, Schreiner \& Mohara 1997; Jakobsen 1987; Lewis \& Koide 1990; Shumway \& Koide 1994), and thus these treatments can potentially affect seed germination. There is surprisingly little research on the impacts of competition on seed characteristics and germination success. However, Platenkamp \& Shaw (1993) found that seeds of Nemophila menziesii were smaller when maternal plants were experiencing competition, and that these seeds also took longer to germinate and were more likely to be dormant. They note that, while size differences in maternal plants appeared to play a role, this factor alone could not account for the reduced size and germination success of seeds produced by maternal plants experiencing competition.

I assessed the possibility that environmental factors may have opposing impacts on different components of fitness using a perennial herbaceous species, Achillea millefolium $\mathrm{L}$. This is a weedy species, found in grassy areas throughout Michigan (Voss 1996). In an earlier study (V.J.A., unpublished results) I found that this species had a positive biomass response to removal of fungi by application of fungicide. Because of this effect, it is likely that fungicide will also have positive effects on seed number (Fig. 1). However, Achillea is mycotrophic (personal observation) and thus presumably relies in part on fungi for nutrient uptake. This suggests that removal of fungi should have a negative effect on tissue nutrient concentrations, and thus seed germination success (Fig. 1). Shoot competition may also have opposing impacts on these two components of fitness. Shoot competition negatively affects light availability and thus carbon fixation, and as a result the concentration of carbon should decline relative to the concentration of other nutrients. Thus shoot competition should negatively affect plant biomass and seed numbers, but because tissue nutrient concentrations increase, seed germination success may be higher (Fig. 1). In contrast, fertilizer addition and root competition are not expected to have opposing effects on the two components of fitness. By increasing nutrient availability, fertilizer should have a positive effect on both seed numbers and germination success, while by reducing nutrient availability, root competition should have negative effects on seed numbers and germination success (Fig. 1). Although the proportion of biomass allocated to flowering could be an important component of seed production, the impact of any of the four treatments on this is unknown, and thus no predictions have been generated for this part of the pathway.

\section{Methods}

This experiment was conducted at the University of Michigan Matthei Botanical Gardens, in south-east Michigan, USA $\left(83^{\circ} 40^{\prime} \mathrm{W}, 42^{\circ} 17^{\prime} \mathrm{N}\right)$, in a field last used for agriculture 40 years ago. Average rainfall recorded at the Ann Arbor weather station is $76 \mathrm{~cm}$, with an average growing season of 174 days. The site is flat and is mowed every year or every second year. Soil is a sandy loam, with $54 \%$ sand, $29 \%$ silt and $17 \%$ clay. The matrix vegetation is composed largely of Poa compressa L., with patchily distributed goldenrod (Solidago spp.) and thistle (Cirsium spp.). 
744

V. J. Allison

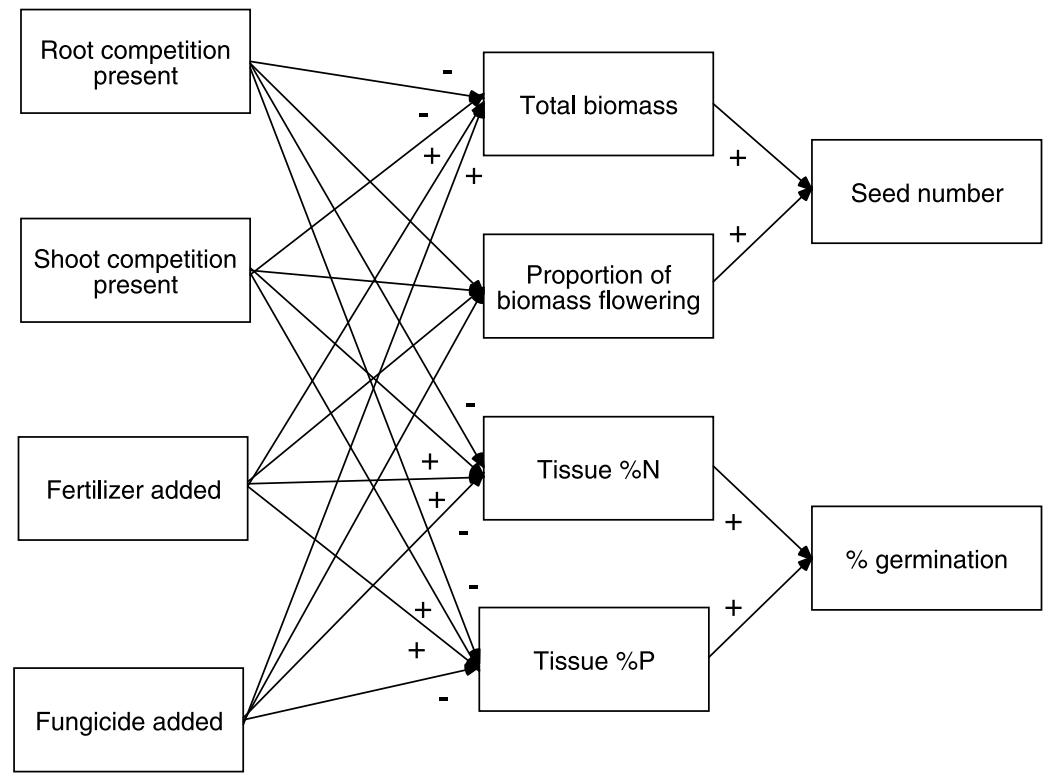

Fig. 1. Hypothesized pathways by which root competition, shoot competition, fertilizer and removal of fungi by fungicide application may affect seed number and germination success. Seed number was hypothesized to be determined largely by plant biomass, while seed germination success depends on tissue nutrient concentrations. The presence of root competition was predicted to negatively affect both total biomass and tissue nutrient concentrations, while the presence of shoot competition was predicted to negatively affect total biomass, but to positively affect tissue nutrient concentrations. Addition of fertilizer was predicted to positively affect both total biomass and tissue nutrient concentrations, while in this species, removal of fungi by application of fungicide was predicted to positively affect total biomass, but to negatively affect tissue nutrient concentrations.

The species studied was Achillea millefolium L., a polyploid complex of native and introduced European plants that freely hybridize (Voss 1996). Achillea is found throughout Michigan in a broad range of habitats, but particularly in grassy, disturbed areas (Voss 1996). This species has a rosette juvenile form and is capable of vegetative spread, with new ramets produced on shallow rhizomes. Despite its capacity for vegetative growth Achillea produces large numbers of seeds, which germinate in large numbers on bare ground throughout the growing season. Flowers are produced on upright stems in many-headed inflorescences, and flowering occurs in midsummer, continuing intermittently through into late summer. At this site flowers were visited frequently by insects, particularly bees. As a result, I did not hand-pollinate the plants used in this experiment, as despite this species' high degree of self-incompatibility (Vetter et al. 1996) it seemed unlikely that pollen would be limiting.

Treatments were randomly assigned to $50 \mathrm{~cm}$ radius plots in each of six blocks. Fertilizer, fungicide, root competition and shoot competition were manipulated independently in a $2 \times 2 \times 2 \times 2$ fully factorial design replicated among the six blocks. Root competition was prevented by driving $30 \mathrm{~cm}$ long, $12 \mathrm{~cm}$ diameter PVC pipes into the ground. After pipes were driven in, one ramet of Achillea was planted into each plot (May

(C) 2002 British Ecological Society, Functional Ecology, 16, $742-749$ 1999). Ramets were collected from this and a neighbouring field, and immediately transplanted into plots. All ramets chosen were vegetative and were measured after transplanting to confirm that there were no sig- nificant differences between the initial size of ramets in each treatment (results not shown).

After planting was complete, other treatments were initiated. Above-ground competition was prevented by holding neighbours back with nylon mesh (Bird-X, Dalen Products, Knoxville, TN, USA). Once a moth throughout the growing season, weeds were pulled from the no-root competition plots, and neighbouring shoots were pulled under the net surrounding the noshoot competition plots. Osmocote slow-release fertilizer (Scotts Company, Marysville, OH, USA) was applied twice in each growing season to give a total fertilizer addition of $6 \mathrm{~g} \mathrm{~N} \mathrm{~m}^{-2}$ year $^{-1}\left(3.5 \mathrm{~g}\right.$ as $\mathrm{N}_{4}^{+}, 2.5 \mathrm{~g}$ as $\mathrm{NO}_{3}^{-}$), $2.6 \mathrm{~g} \mathrm{P} \mathrm{m}^{-2}$ year $^{-1}$ and $5 \mathrm{~g} \mathrm{~K} \mathrm{~m}^{-2}$ year $^{-1}$. The systemic fungicide Benomyl (DuPont, Wilmington, DE, USA) was applied as a drench, at a rate of $0.375 \mathrm{~g}$ per plot (active ingredient dissolved in 21 water) every 2 weeks throughout the growing season to prevent re-infection. Control plots received an equal volume of water. This application regime significantly reduced AM fungi infection in soils with a similar texture (Hartnett et al. 1994). A potential problem is that no fungicide is specific to AM fungi, and so pathogenic, endophytic and saprophytic fungi may also be affected.

To assess the impact of treatments on environmental variables, light and soil nutrients were measured prior to plant harvest at the end of the second growing season. Light availability in each plot was measured at a point $5 \mathrm{~cm}$ above the soil surface with a Sunfleck Ceptometer (Decagon, Pullman, WA, USA), and recorded 
Environmental impacts on fitness of Achillea

(C) 2002 British

Ecological Society, Functional Ecology, 16, $742-749$ as percentage of full light. One soil core was taken from each plot and frozen until nutrients were extracted. Nutrients were extracted from $5 \mathrm{~g}$ soil in $50 \mathrm{ml} 2 \mathrm{M} \mathrm{KCl}$. Extraction of $\mathrm{P}$ with $2 \mathrm{M} \mathrm{KCl}$ is adequate for treatment comparisons, but is not a good indicator of total available $\mathrm{P}$ in the soil. However, because of time and financial constraints, the same extraction procedure was used for all soil nutrients. Nitrate in extracts was analysed on a Lachat flowinjection analyser (FIA) using the cadmium-reduction method, while ammonium was analysed on an FIA using the salicylate method. Phosphorus was measured on an FIA using the ammonium molybdateantimony potassium tartrate method. Extracts were analysed at the Soil and Plant Testing Laboratory, Michigan State University.

In the second growing season, seeds were collected by cutting off the seed heads once dry (August into September 2000). Seeds were extracted from the heads using a seed blower. Total seed fresh weight and average individual seed weight were measured for a subset of the seeds, while total seed number was calculated by dividing total seed weight by the average individual seed weight. At the end of the second growing season (September 2000), above-ground biomass was harvested, divided into vegetative and flowering biomass, and the number of ramets of each counted. Roots were harvested in three of the six blocks, and washed clean under a hose. All biomass was dried at $65^{\circ} \mathrm{C}$ for $48 \mathrm{~h}$, to constant weight, and then weighed. Root samples from two blocks were stained with aniline blue using a cold-staining technique (York Mycorrhiza Research Group 1999), and percentage infection was determined by the intercept method. On each root sample, 100 root intercepts were examined. The number of intercepts with hyphae, vesicles, arbuscules or spores were summed, and divided by the total number of root intercepts examined to give a percentage infection.

To determine tissue nutrient concentrations, dried vegetative biomass was ground using a Cyclotex 1093 sample mill. Tissue was analysed for total $\mathrm{C}$ and $\mathrm{N}$ concentrations using a $\mathrm{CHN}$ autoanalyser. To assess tissue $\mathrm{P}$ concentration, ground tissue was dry-ashed at $500{ }^{\circ} \mathrm{C}$ for $5 \mathrm{~h}$, and the ash digested in $3 \mathrm{~m}$ nitric acid. The resulting digest was analysed on an FIA using the ammonium molybdate-antimony potassium tartrate method at the Soil and Plant Testing Laboratory, Michigan State University.

To test germination success, seeds were planted on nutrient-free agar plates, with one plate for each replicate of each treatment. One hundred seeds were sown on each plate, except in cases when the number of seeds produced was very small, in which case all available seeds were sown. Plates were wrapped in parafilm to reduce water loss and placed under grow-lights in a laboratory. Day length was set at $16 \mathrm{~h}$ and, while not controlled, the ambient temperature throughout the germination experiment was $c .20^{\circ} \mathrm{C}$. To make seedling harvest easy, plates were oriented vertically. This results in roots growing across, rather than into, the agar surface. Germination was observed 3 days after planting, and percentage germination calculated. Seedlings were harvested 4 days after germination. This early harvest ensured that subsequent growth did not obscure differences in seedling size due to maternal effects.

Path analysis was used to determine the relative importance of the various mechanisms by which treatments affected seed number and germination. Path analysis is a means of quantifying an otherwise qualitative model of how variables interact (Wootton 1994; Wright 1934). To perform path analysis, an a priori hypothetical diagram is constructed (Figure 1) showing the functional relationship among variables (Wootton 1994). For each connecting path between variables, a path coefficient can be calculated. These path coefficients are equivalent to the standardized partial regression coefficients of multiple regression, and represent the effect of one variable on another dependent variable, with all other variables statistically held constant (Mitchell 1992). In addition to determining the relationship among variables within the model, path analysis can be used to test how well a hypothetical model fits the data.

Path analysis was performed in Amos 4.0 (Arbuckle 1999). Data were transformed for the path analysis as necessary to meet assumptions of normality and homogeneity of variance: percentage $\mathrm{N}$ and $\mathrm{P}$ in tissues were left untransformed, while natural logtransformed data were used for total biomass and seed number, an arcsine transformation was used for proportion of tissue allocated to flowering, and a square root transformation was used for percentage germination. The test statistic $\left(\chi^{2}\right)$ measures the overall fit of the model (Mitchell 1992). This tests the null hypothesis that there is no significant difference between the data and the proposed model (Mitchell 1992). A significant $\chi^{2}(P<0.05)$ indicates that the null model should be rejected, because the model and data are significantly different. Parametric statistics were performed in SYSTAT 9 (SYSTAT, 1998).

\section{Results}

The full model proposed does not effectively fit the data $\left(\chi^{2}=101 \cdot 180, P=0 \cdot 0001\right)$. It does, however, explain $c .72 \%$ of the variation in the number of seeds produced and $19 \%$ of the variation in the proportion of seeds that germinated (Fig. 2). Contrary to prediction (Fig. 1), root competition increased the percent of tissue composed of $\mathrm{P}$ but decreased total biomass, the proportion of biomass devoted to flowering, and the percent of tissue composed of N (Fig. 2). Shoot competition decreased total biomass, but had little impact on the proportion of biomass devoted to flowering, or the $\mathrm{N}$ or $\mathrm{P}$ concentration in tissues (Fig. 2). Fertilizer increased the $\mathrm{N}$ concentrations in tissues, while removal of fungi by application of fungicide increased 
746

V. J. Allison

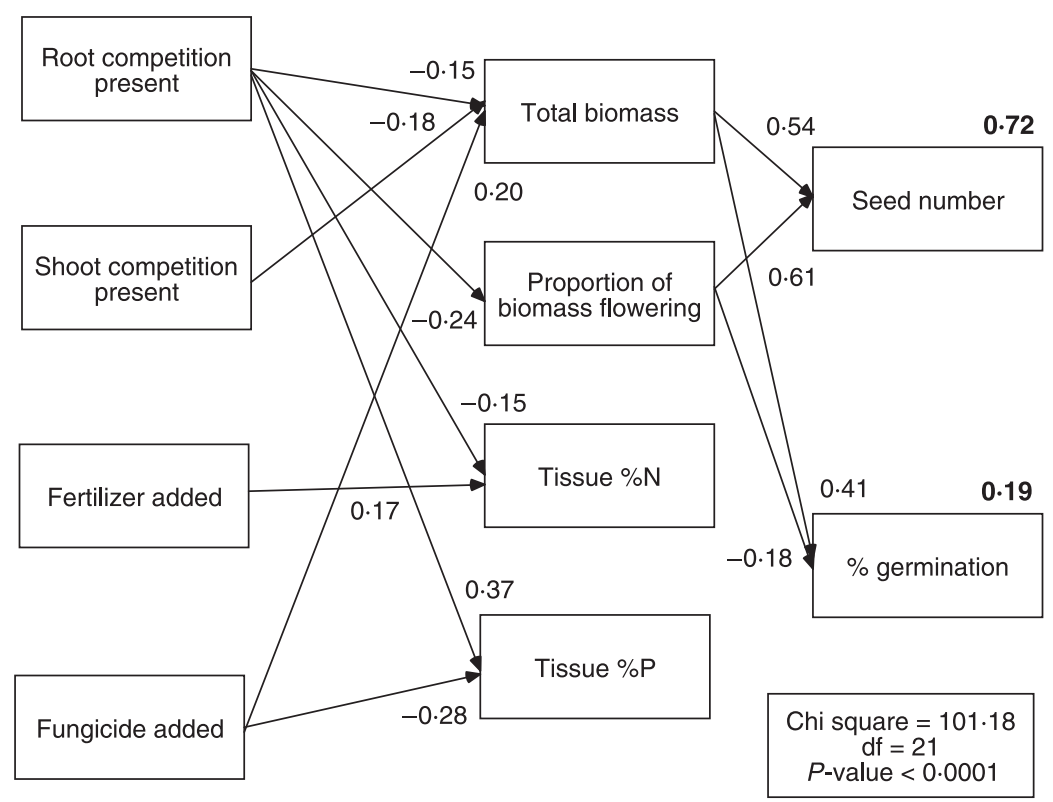

Fig. 2. Full path model showing the pathways by which root competition, shoot competition, fertilizer and fungicide affect seed number and seed germination success in field-grown individuals of Achillea millefolium. Numbers in bold are squared multiple correlations over all paths; numbers in plain text are partial correlation coefficients. Only paths with correlation coefficients $>0 \cdot 15$ are included as correlations lower than this were unlikely significantly to influence seed number or success under field conditions. This model explains $72 \%$ of the variation in seed number, but only $19 \%$ of the variation in germination success. Total biomass positively affects both seed number and germination success, while the proportion of biomass allocated to flowering positively affects seed number, but negatively affects germination success. Tissue nutrient concentrations have no effect on either seed number or germination success. The hypothesized model does not adequately fit the data $\left(\chi^{2}=101 \cdot 18, P=0 \cdot 000\right)$.

total biomass but decreased tissue $\mathrm{P}$ concentrations (Fig. 2). Total biomass increased both seed number and seed germination, while the proportion of tissue devoted to flowering increased seed number but decreased percentage germination (Fig. 2). Surprisingly, tissue nutrient concentrations had little effect on the proportion of seeds that germinated.

A reduced version of the full model provided an adequate fit to the data $\left(\chi^{2}=18 \cdot 261, P=0.249\right)$. This model was able to explain c. $62 \%$ of the variation in the number of seeds produced, and c. $16 \%$ of the variation in the proportion of seeds that germinated (Fig. 3). Root competition and shoot competition both negatively affected total biomass, while fertilizer and removal of fungi by application of fungicide positively affected biomass (Fig. 3). However, together these variables explained only $11 \%$ of the variation in total biomass. Root and shoot competition negatively affected both seed number and germination success, while fertilizer and removal of fungi by fungicide application both positively affected seed number and had slight positive effects on percentage germination (Table 1).

Several other models were tested, including one model with tissue $\mathrm{C}$ concentration rather than $\mathrm{N}$ or $\mathrm{P}$ concentrations, and several reduced models with proportion of biomass allocated to flowering substituted for biomass, and with the effect of mean seed size on

(C) 2002 British Ecological Society, Functional Ecology, 16, $742-749$ percentage germination mediating the impact of biomass on germination success. However, none of these models provided an adequate fit to the data (results not shown).
Table 1. Partial correlation coefficients of treatment effects on seed number and percentage germination, from the reduced model (Fig. 3)

\begin{tabular}{lcc}
\hline Treatment & $\begin{array}{l}\text { Seed } \\
\text { number }\end{array}$ & $\begin{array}{l}\text { Percentage } \\
\text { germination }\end{array}$ \\
\hline Root competition present & $-0 \cdot 117$ & $-0 \cdot 059$ \\
Shoot competition present & $-0 \cdot 143$ & $-0 \cdot 072$ \\
Fertilizer added & $0 \cdot 096$ & $0 \cdot 048$ \\
Fungicide applied & $0 \cdot 154$ & $0 \cdot 078$ \\
\hline
\end{tabular}

To test the effectiveness of treatments, I measured light penetration, availability of nitrate, ammonium and phosphorus, and AM fungal infection in roots. The shoot competition treatment was designed to influence light penetration through the vegetation. The treatment successfully reduced light penetration, and no other treatment affected this variable (Table 2). There were no significant treatments effects on availability of $\mathrm{NH}_{4}^{+}$(results not shown). The nitrate pool was significantly increased by fertilizer application, as intended. However, shoot competition also significantly increased nitrate availability (Table 2). The available P pool was greatly reduced by root competition and fungicide, and greatly increased by fertilizer addition (Table 2). However, because of large variation, only the effect of fungicide was statistically significant. As expected, fungicide significantly reduced AM fungal infection in the roots (Table 2). Infection was also reduced by fertilizer and root competition (Table 2). 
747

Environmental impacts on fitness of Achillea

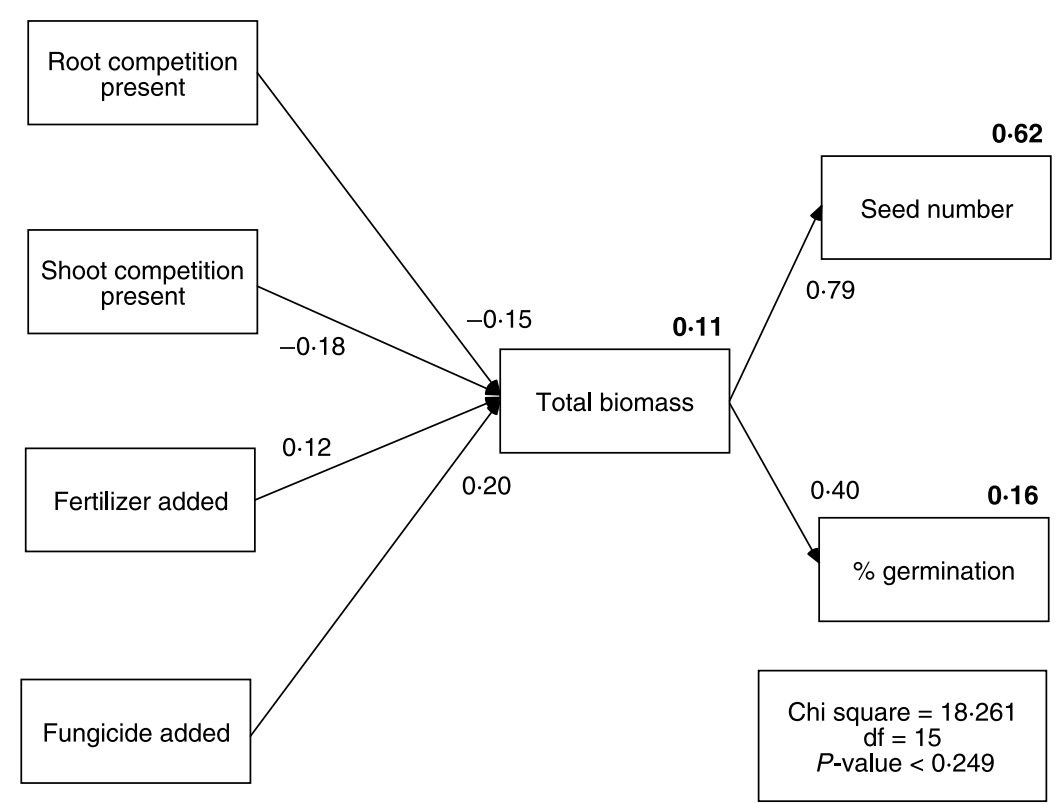

Fig. 3. Reduced path model showing the pathway by which root competition, shoot competition, fertilizer and fungicide affect seed number and seed germination success in field-grown individuals of Achillea millefolium. Numbers in bold are squared multiple correlations over all paths; numbers in plain text are partial correlation coefficients. This model explains $62 \cdot 2 \%$ of the variation in seed number, and $15 \cdot 8 \%$ of the variation in germination success, both of which are positively related to total biomass. Root and shoot competition negatively affects total biomass, while fertilizer and fungicide application increased biomass (see Table 1 for summary of results). This model provides an adequate fit to the data $\left(\chi^{2}=18 \cdot 261, P=0 \cdot 249\right)$.

Table 2. Impact of experimental treatments on environmental variables (expressed as percentage of control levels)

\begin{tabular}{|c|c|c|c|c|c|}
\hline \multirow[b]{2}{*}{ Treatment } & \multirow[b]{2}{*}{$\mathrm{df}$} & \multicolumn{4}{|c|}{ Percentage of control } \\
\hline & & Light & Nitrate & Phosphorus & Infection \\
\hline With root competition & 1 & $82 \cdot 1$ & $64 \cdot 9$ & $44 \cdot 5$ & $57 \cdot 3^{*}$ \\
\hline With shoot competition & 1 & $22 \cdot 4 * * *$ & $185 \cdot 7^{*}$ & $81 \cdot 8$ & $86 \cdot 5$ \\
\hline Fertilizer added & 1 & $101 \cdot 8$ & $193 \cdot 2^{*}$ & $274 \cdot 7$ & $37 \cdot 3^{*}$ \\
\hline Fungicide applied & 1 & $69 \cdot 9$ & $69 \cdot 9$ & $23 \cdot 1^{*}$ & $30 \cdot 8^{*}$ \\
\hline
\end{tabular}

Statistical significance of treatments was determined using a fully factorial ANOvA. There were no interactions between treatments. Data did not require transformation, except for phosphorus, which was natural log-transformed prior to analysis to meet assumption of homogeneity of variance. ( $, P=0 \cdot 05, * *, P=0 \cdot 001$, ***, $P=0.0001)$.

A potential problem with using fungicide is that there is no fungicide specific to AM fungi. Fungicides also affect saprophytic, endophytic and pathogenic fungi. In this study, evidence suggests that reduction in infection by AM fungi is the major cause of the plant response to fungicide. It does not appear to be due to increased nutrient availability resulting from increased mineralization of dead fungi, as fertilizer and fungicide do not have the same effects on plants. Fertilizer increased plant $\mathrm{N}$ but had only slight positive effects on plant $\mathrm{P}$, while fungicide had little effect on $\mathrm{N}$ but decreased plant $\mathrm{P}$ concentration (Fig. 2). Further, fertilizer increased soil nitrate and $\mathrm{P}$ availability, while fungicide reduced concentrations of these nutrients (Table 2).

(C) 2002 British Ecological Society, Functional Ecology, 16, $742-749$

\section{Discussion}

Plant fitness depends on the number of seeds produced and the proportion of those seeds that germinate. Both can be influenced by the environment of the maternal plant, and environmental conditions which are beneficial to one component of fitness will not necessarily be so to another. It was hypothesized that the number of seeds produced would be positively influenced by the total biomass of the plant and the proportion of that biomass devoted to flowering, while germination success would depend on tissue nutrient concentrations (Fig. 1).

Both the full and reduced model supported one part of these hypotheses: total biomass has a significant positive effect on seed number (Figs 2 and 3). As found by Weiner et al. (1997) and Cheplick (2001), treatments applied to maternal plants affected plant size, and thus the number of seeds produced. As a result, treatments that had a positive effect on plant biomass also positively affected seed number and vice versa: root competition and shoot competition decreased, while fertilizer and fungicide increased seed number (Table 1). The importance of biomass in determining 
seed output was previously noted by Samson \& Werk (1986). In a review that included both annual and perennial species, they found that much of the variation in reproductive output observed was the result of variation in plant size.

Although, as predicted, seed number increased in response to removal of AM fungi by fungicide application, this result is not consistent with all previous studies. For example, Stanley, Koide \& Shumway (1993) found that AM fungi increased seed production by Abutilon theophrasti. The apparent contradiction between these two studies is due to differences in the impact of AM fungi on biomass. Under the experimental conditions, Abutilon biomass increased in response to AM fungi, while Achillea biomass declined. Exactly why Achillea biomass declines when fungi are present is unclear. Although one possibility is that the carbon drain to the fungi is inhibitory, the same response is seen even in the absence of competition (results not shown), when $\mathrm{C}$ should not be limiting. An alternative possibility is that the fungicide is also controlling non-AM fungi. Newsham, Fitter \& Watkinson. (1994) found a similar positive affect of the fungicide Benomyl on seed number, and attributed this to a decrease in root pathogens.

In contrast to my predictions, tissue nutrient concentrations had very little effect on seed germination success. Instead, total biomass positively influenced the percentage of seeds that germinated (Fig. 2). This result is not unique: Steinger, Gall \& Schmid (2000) similarly found no relationship between seed size and germination success in seeds of Bromus erectus grown under ambient and elevated $\mathrm{CO}_{2}$, despite large differences in seed size and $\mathrm{C}: \mathrm{N}$ ratios. In the current study, treatments that influenced germination did so though changes in biomass rather than changes in tissue nutrients. It is not clear why total plant biomass was positively related to seed success. Although the impact of plant biomass on seed germination might be mediated through changes in $\mathrm{C}$ concentration in maternal tissues, or seed size, neither was found to be an important factor determining germination success (results not shown).

The low variation found in seed germination success may be due to ovule abortion. Andersson (1993) found high rates of ovule abortion in Achillea ptarmica, with a lower proportion of ovules aborted under optimal conditions. This suggests that in this genus, nutrient availability alters seed numbers rather than quality. Ovule abortion may also account for the generalization that, while in many cultivated species seed nutrient concentrations are markedly affected by the nutrient supply to the maternal plant, in wild plants the composition of the seeds remains relatively constant (for review see Roach \& Wulff 1987).

Because biomass had significant positive impacts on both seed number and germination success, the hypothesis that some treatments would have positive effects on one component of fitness, but negative effects on another, was not supported. There was, how- ever, some evidence for the potential for opposing impacts of fitness: removal of fungi by application of fungicide did have positive effects on biomass of this species, while simultaneously reducing $\mathrm{P}$ concentrations (Fig. 2). In species where seed germination is more responsive to nutrient availability, measurements made in terms of biomass may not be effective determinants of fitness. Whether changes in germination success can outweigh changes in seed number under field conditions is not clear. Although some studies find positive impacts of nutrient levels on seed size and subsequent germination, these experiments commonly use uniform maternal plants and controlled environments (e.g. Sills \& Nienhuis 1995, who used genetically uniform, inbred Arabidopsis thaliana). In less uniform populations growing in less constant environments, it seems probable that the impact of the environment on seed number will outweigh any response in terms of seed quality. This finding suggests that in ecological studies, measures of biomass are a good surrogate for fitness in herbaceous plants.

\section{Acknowledgements}

Thanks to the staff of the University of Michigan Matthei Botanical Gardens for field and greenhouse assistance, and to Marc Ammerlaan for pouring the plates. Thanks also to Deborah Goldberg, Mike Miller and Tara Rajaniemi for helpful discussions. This work was supported by grants from the Matthei Botanical Gardens and the University of Michigan Department of Biology.

\section{References}

Aarssen, L.W. \& Burton, S.M. (1990) Maternal effects at four levels in Senecio vulgaris Asteraceae grown on a soil nutrient gradient. American Journal of Botany 77, 1231-1240.

Al-Kariki, G.N. \& Clark, R.B. (1999) Mycorrhizal influence on protein and lipid of durum wheat grown at different soil phosphorus levels. Mycorrhiza 9, 97-101.

Andersson, S. (1993) The potential for selective seed maturation in Achillea ptarmica (Asteraceae). OIKOS 66, 36-42.

Arbuckle, J.L. (1999) Amos 4·01. Smallwaters Corp., Chicago, IL, USA.

Begon, M., Harper, J.L. \& Townsend, C.R. (1996) Ecology. Blackwell Science, Oxford, UK.

Bethlenfalvay, G.J., Schreiner, R.P. \& Mohara, K.L. (1997) Mycorrhizal fungi effects on nutrient composition and yield of soybean seeds. Journal of Plant Nutrition 20, 581591.

Bryla, D.R. \& Koide, R.T. (1990) Regulation of reproduction in wild and cultivated Lycopersicon esculentum Mill. by vesicular-arbuscular mycorrhizal infection. Oecologia 84, $74-81$.

Cheplick, G.P. (2001) Quantitative genetics of mass allocation and the allometry of reproduction in Amaranthus albus: relation to soil nutrients. International Journal of Plant Science 162, 807-816.

Cheplick, G.P. \& Sung, L.Y. (1998) Effects of maternal nutrient environment and maturation position on seed heteromorphism, germination, and seedling growth in Triplasis purpurea (Poaceae). International Journal of Plant Science 159, 338-350. 
Environmental impacts on fitness of Achillea
Grace, J.B. \& Tilman, D. (1990) Perspectives on Plant Competition. Academic Press, London.

Hartnett, D.C., Samenus, R.J., Fischer, L.E. \& Hetrick, B.A.D. (1994) Plant demographic responses to mycorrhizal symbiosis in tallgrass prairie. Oecologia 99, 21-26.

Holt, N.W. (1988) Effect of nitrogen fertilizer on the agronomic performance and seed quality of annual canarygrass. Canadian Journal of Plant Science 68, 41-46.

Jakobsen, I. (1987) Effects of VA mycorrhiza on yield and harvest index of field-grown pea. Plant and Soil 98, 407416.

Lewis, J.D. \& Koide, R.T. (1990) Phosphorus supply, mycorrhizal infection and plant offspring vigour. Functional Ecology 4, 695-702.

Mitchell, R.J. (1992) Testing evolutionary and ecological hypotheses using path analysis and structural equation modeling. Functional Ecology 6, 123-129.

Newsham, K.K., Fitter, A.H. \& Watkinson, A.R. (1994) Root pathogenic and arbuscular mycorrhizal fungi determine fecundity of asymptomatic plants in the field. Journal of Ecology 82, 805-814.

Parrish, J.A.D. \& Bazzaz, F.A. (1985) Nutrient content of Abutilon theophrasti seeds and the competitive ability of the resulting plants. Oecologia 65, 247-251.

Platenkamp, G.A.J. \& Shaw, R.G. (1993) Environmental and genetic maternal effects on seed characters in Nemophila menziesii. Evolution 47, 540-555.

Raven, P.H., Evert, R.F. \& Eichhorn, S.E. (1999) Biology of Plants. W.H. Freeman, New York.

Read, D.J. (1991) Mycorrhizae in ecosystems. Experientia 47, 376-391.

Roach, D.A. \& Wulff, R.D. (1987) Maternal effects in plants. Annual Review of Ecology and Systematics 18, 209-235.

Samson, D.A. \& Werk, K.S. (1986) Size-dependent effects in the analysis of reproductive effort in plants. American Naturalist 127, 667-680.

Shumway, D.L. \& Koide, R.T. (1994) Within-season variability in mycorrhizal benefit to reproduction in Abutilon theophrasti Medic. Plant, Cell and Environment 17, 821-827.
Sills, G.R. \& Nienhuis, J. (1995) Maternal phenotypic effects due to soil nutrient levels and sink removal in Arabidopsis thaliana (Brassicaceae). American Journal of Botany 82, 491-495.

Stanley, M.R., Koide, R.T. \& Shumway, D.L. (1993) Mycorrhizal symbiosis increases growth, reproduction and recruitment of Abutilon theophrasti Medic. in the field. Oecologia 94, 30-35.

Steinger, T., Gall, R. \& Schmid, B. (2000) Maternal and direct effects of elevated $\mathrm{CO}_{2}$ on seed provisioning, germination and seedling growth in Bromus erectus. Oecologia 123, 475-480.

SYSTAT (1998) SYSTAT. SPSS Inc., Richmond, CA, USA.

Vetter, S., Lambrou, M., Franz, C., Ehrendorfer, F. \& Saukel, J. (1996) Chromosome numbers of experimental tetraploid hybrids and self-pollinated progenies with the Achillea millefolium complex (Compositae). Caryologia 49, 227-231.

Voss, E.G. (1996) Michigan Flora. Part III: Dicots Concluded, pp. 399-400. Cranbrook Institute of Science, Bloomfield Hills, MI, USA.

Weiner, J., Martinez, S., Mueller-Schaerer, H., Stoll, P. \& Schmid, B. (1997) How important are environmental maternal effects in plants? A study with Centaurea maculosa. Journal of Ecology 85, 133-142.

Wootton, J.T. (1994) Predicting direct and indirect effects: an integrated approach using experiments and path analysis. Ecology 75, 151-165.

Wright, S. (1934) The method of path coefficients. Annals of Mathematical Statistics 5, 161-215.

Wulff, R.D., Causin, H.F., Benitez, O. \& Bacalini, P.A. (1999) Intraspecific variability and maternal effects in the response to nutrient addition in Chenopodium album. Canadian Journal of Botany 77, 1150-1158.

York Mycorrhiza Research Group. (1999) Techniques in Arbuscular Mycorrhiza Research. University of York, York, UK.

Received 6 December 2001; revised 17 June 2002; accepted 19 June 2002
(C) 2002 British

Ecological Society, Functional Ecology, 16, 742-749 